\title{
Synthesis and Preliminary Characterization of a PPE-Type Polymer Containing Substituted Fullerenes and Transition Metal Ligation Sites
}

\author{
Corinne A. Basinger, Kaitlin Sullivan, Sarah Siemer, Stuart Oehrle, and Keith A. Walters \\ Department of Chemistry, Northern Kentucky University, Nunn Drive, Highland Heights, KY 41099, USA \\ Correspondence should be addressed to Keith A. Walters; walterske@nku.edu
}

Received 1 July 2015; Revised 21 September 2015; Accepted 8 October 2015

Academic Editor: Davide Vione

Copyright (C) 2015 Corinne A. Basinger et al. This is an open access article distributed under the Creative Commons Attribution License, which permits unrestricted use, distribution, and reproduction in any medium, provided the original work is properly cited.

\begin{abstract}
A substituted fullerene was incorporated into a PPE-conjugated polymer repeat unit. This subunit was then polymerized via Sonogashira coupling with other repeat units to create polymeric systems approaching 50 repeat units (based on GPC characterization). Bipyridine ligands were incorporated into some of these repeat units to provide sites for transition metal coordination. Photophysical characterization of the absorption and emission properties of these systems shows excited states located on both the fullerene and aromatic backbone of the polymers that exist in a thermally controlled equilibrium. Future work will explore other substituted polyaromatic systems using similar methodologies.
\end{abstract}

\section{Introduction}

Since their discovery, fullerenes have been a focus of photochemistry and molecular electronics for their unique properties, and our group has been interested for many years in their incorporation into supramolecular systems [1-3]. Our focus has been the substituted fullerene 1 (Scheme 1) that provides a simple "handle" for attachment to other moieties [4-6]. Our initial efforts focused on small molecule systems incorporating well-known transition metal chromophores (e.g., $-\mathrm{Re}^{\mathrm{I}}(\mathrm{CO}){ }_{3} \mathrm{Cl}$ and $-\mathrm{Ru}^{\mathrm{II}}(\mathrm{bpy})_{2}{ }^{2+}$, where bpy is $2,2^{\prime}-$ bipyridine) [7-9] that exhibited unique photophysical properties, including photoinduced charge transfer [6]. These charge transfer capabilities have been further confirmed with $a b$ initio calculations [10]. Of particular interest is our ultimate design to prepare fullerene/transition metal sensitizers for solar cells [11-17].

Although our small molecule work produced interesting results, the ultimate goal of our research is to produce polymeric systems containing these moieties and understanding their photoinduced excited-state behavior. While there has been considerable interest in the research community that incorporate fullerene $\mathrm{C}_{60}$ into $\pi$-conjugated polymeric systems for nearly a decade (some containing transition metal chromophores) [18-35], these systems use relatively complicated structures that do not facilitate efficient electronic communication between the two moieties [36, 37]. In contrast, our relatively simple synthetic strategy provides a more robust connection between the subunits and presumably more efficient electronic interactions.

Herein we report our recent synthetic efforts to incorporate 1 into $\pi$-conjugated polyphenyleneethynylene- (PPE-) type polymeric systems. These polymers represent systems containing pendant fullerenes (described by others as "bucky ball fishing") [27], which provides a nice balance of fullerene loading and a well-defined repeat structure. Key to these efforts is the design of repeat unit $\mathbf{2}$ (Scheme 2) that connects $\mathbf{1}$ to an aromatic "hub" with two halides that can be utilized in polymerization reactions involving Sonogashira coupling [38]. Dialkynes needed for the coupling reaction will provide ligation points for transition metal chromophores through the incorporation of a $2,2^{\prime}$-bipyridyl moiety within the repeat unit (4, Scheme 4). Alternatively, substituted benzene (3, Scheme 3) can instead be polymerized to provide a variety of polymeric options with varying moieties present $(\mathbf{5}, \mathbf{6}$, and 7 , Scheme 4). Along with preliminary photophysical 


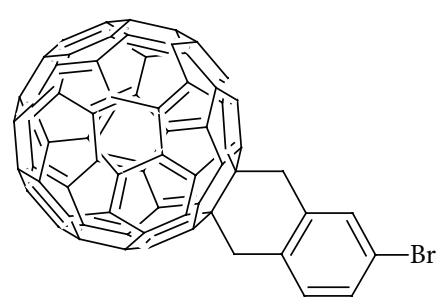

1

SCHEme 1: Structure of substituted fullerene 1.

characterization of these systems, we report efforts to characterize molecular weights of these fullerene-containing systems via gel permeation chromatography (GPC).

\section{Materials and Methods}

2.1. Materials and Instrumentation. $\mathrm{C}_{60}$ and $\mathrm{C}_{70}$ standards were obtained from Sigma Aldrich (St. Louis, MO, USA). All solvents used were of HPLC grade or higher. Individual polystyrene standards used for gel permeation chromatography (GPC) were from Waters Corporation (Milford, MA, USA) and were at a molecular weight of 456, 1050, 5970, and $2630 \mathrm{~g} / \mathrm{mol}$. These standards were prepared at a concentration of $0.2 \%$ (by weight) in tetrahydrofuran (THF) individually.

Chemicals were purchased from Aldrich, Alfa Aesar, GFS, and Spectra Group Limited and used as received unless otherwise indicated. Compounds $\mathbf{1 , 4}$, and $\mathbf{1 0}$ were prepared as previously reported $[4,6,39]$. Molecular characterization is based on spectra data $\left({ }^{1} \mathrm{H}\right.$ NMR, IR) and physical data reported in previous documented procedures for the smaller subunits. Spectroscopic instrumentation utilized is identical to that reported previously [6].

2.2. Synthesis of Central Hub Precursor (8). In a $100.0 \mathrm{~mL}$ Schlenk flask equipped with a stir bar, 1,3-dibromo-5-iodobenzene $(0.5000 \mathrm{~g}, 1.382 \mathrm{mmol}), \mathrm{PdCl}_{2}\left(\mathrm{PPh}_{3}\right)_{2}(0.0479 \mathrm{~g}$, $0.0682 \mathrm{mmol})$, and $\mathrm{CuI}(0.4057 \mathrm{~g}, 2.130 \mathrm{mmol})$ were added. This flask was connected to a condenser and then purged and filled with argon. Through the sidearm of the condenser, $7.0 \mathrm{~mL}$ of distilled triethylamine was added via a purged and filled airtight syringe. $10.0 \mathrm{~mL}$ of distilled toluene was added in the same manner. Approximately $10.0 \mathrm{~mL}$ of trimethylsilylacetylene (TMS acetylene) was bubbled with argon for about $10 \mathrm{~min}$ to remove oxygen; then a portion $(0.2164 \mathrm{~mL}$, $1.520 \mathrm{mmol}$ ) was added via airtight syringe to the reaction mixture. The reaction flask was lowered into an oil bath and heated to $80^{\circ} \mathrm{C}$. The reaction refluxed for 20 hours. After reflux, the solvent was removed from the black grainy solution via rotary evaporation. The remaining solid was extracted with $10 \mathrm{~mL}$ of ethyl acetate and sonication for 10 minutes. The mixture was then filtered and washed with ethyl acetate. A brownish/gray solid was filtered out and the brown filtrate was rotovapped to produce product 8 in quantitative yield. ${ }^{1} \mathrm{H}$ NMR $\left(500 \mathrm{MHz}, \mathrm{CDCl}_{3}\right.$ ): $\delta 0.25$ (s, 9H), 7.51 (dd, $\mathrm{Ph}, 2 \mathrm{H}), 7.58$ (s, $\mathrm{Ph}, 1 \mathrm{H})$.
2.3. Deprotection of $\mathbf{8}$ (9). In a $250 \mathrm{~mL}$ round bottom flask equipped with a stir bar, $8(0.2380 \mathrm{~g}, 0.7166 \mathrm{mmol}), 20.0 \mathrm{~mL}$ distilled and degassed THF, $6.0 \mathrm{~mL}$ of $20 \%$ (w/v) $\mathrm{NaOH}$ solution, and $37.0 \mathrm{~mL}$ of methanol were added. The solution was stirred vigorously for 2 hours at room temperature, producing an orange solution. Once the stirring was complete, $50 \mathrm{~mL}$ of water was added to the flask producing a white cloudy precipitate. Following the addition of $40 \mathrm{~mL}$ of chloroform, the mixture was filtered to remove the white precipitate. The filtrate was then placed in a separatory funnel and the organic layer collected. Following drying with sodium sulfate, the solution was rotovapped to produce yellowish/orange solid 9 in quantitative yield. IR (ATR, $\mathrm{cm}^{-1}$ ) 1744.38, 1764.81, 2847.67, 2921.23, 3060.161, 3284.90. ${ }^{1} \mathrm{H}$ NMR (500 MHz, $\left.\mathrm{CDCl}_{3}\right) \delta 3.16$ (s, acetylene, H), 7.54 (bs, Ph, 2H), 7.64 (s, Ph, H).

2.4. Attachment of Substituted Fullerene 1 to 9 (2). In a $100 \mathrm{~mL}$ Schlenk flask 9 (0.0145 g, $0.0558 \mathrm{mmol}), 1[4,6](0.0423 \mathrm{~g}$, $0.0468 \mathrm{mmol}), \mathrm{PdCl}_{2}\left(\mathrm{PPh}_{3}\right)_{2}(0.008 \mathrm{~g}, 0.0114 \mathrm{mmol})$, and $\mathrm{CuI}$ $(0.065 \mathrm{~g}, 0.3413 \mathrm{mmol})$ were added along with a stir bar. A condenser was added, and the apparatus was purged and filled with argon. Through the top of the condenser, $7.0 \mathrm{~mL}$ of distilled trimethylamine and $10.0 \mathrm{~mL}$ of distilled toluene were added via a purged and filled airtight syringe. The apparatus was lowered into an $80^{\circ} \mathrm{C}$ oil bath and heated for 24 hours. The solvent was removed from the reaction mixture via rotary evaporation, and the dark reddish brown oily solid was extracted with $10 \mathrm{~mL}$ of ethyl acetate and 10 minutes of sonication. The remaining solid was removed via filtration, and the filtrate was rotovapped to produce crude product 2 as a brownish oil. The product was purified via medium pressure liquid chromatography (MPLC) on silica. The product eluted at $70: 30$ hexanes : ethyl acetate, yield $46 \%$. IR (ATR, $\mathrm{cm}^{-1}$ ) 788.20, 1008.85, 1258.12, 2966.17. ${ }^{1} \mathrm{H}$ NMR $\left(500 \mathrm{MHz}, \mathrm{C}_{6} \mathrm{D}_{6}\right)$ $\delta 5.28\left(\mathrm{~s}, \mathrm{CH}_{2}, 2 \mathrm{H}\right), 5.30\left(\mathrm{~s}, \mathrm{CH}_{2}, 2 \mathrm{H}\right), 7.03(\mathrm{~d}, \mathrm{Ph}, 1 \mathrm{H}), 7.05$ (dd, Ph, 1H), 7.67 (bs, Ph, 1H), 7.69 (dd, Ph, 2H), 7.70 (s, Ph, $1 \mathrm{H})$.

2.5. Synthesis of 1,4-Dimethoxy-2,5-[bis-trimethylsilylacetyl]benzene (11). In a $100.0 \mathrm{~mL}$ Schlenk flask equipped with a stir bar, 10 (0.2500 g, $0.641 \mathrm{mmol}), \mathrm{PdCl}_{2}\left(\mathrm{PPh}_{3}\right)_{2}(0.0442 \mathrm{~g}$, $0.0632 \mathrm{mmol})$, and $\mathrm{CuI}(0.3762 \mathrm{~g}, 1.976 \mathrm{mmol})$ were added. A condenser was added, and the apparatus was purged and filled with argon. Through the sidearm of the flask, $5.0 \mathrm{~mL}$ of distilled triethylamine and $10.0 \mathrm{~mL}$ of distilled toluene were added via a purged and filled airtight syringe. Lastly, $15 \mathrm{~mL}$ of TMS acetylene was placed in a small round bottom flask and was degassed with argon for about $10 \mathrm{~min}$ before it was added through the sidearm of the Schlenk flask $(0.1916 \mathrm{~mL}$, $1.346 \mathrm{mmol}$ ) with a purged and filled airtight syringe. The apparatus was lowered into an $80^{\circ} \mathrm{C}$ oil bath and heated for 24 hours. The solvent was removed from the light orange reaction mixture via rotary evaporation, and the solid was extracted with $10 \mathrm{~mL}$ of ethyl acetate and 10 minutes of sonication. The remaining solid was removed via filtration, and the filtrate was rotovapped to produce crude product $\mathbf{1 1}$ as a grayish/gold solid. The product was purified via MPLC on silica. The product eluted at 70:30 hexanes : ethyl acetate 


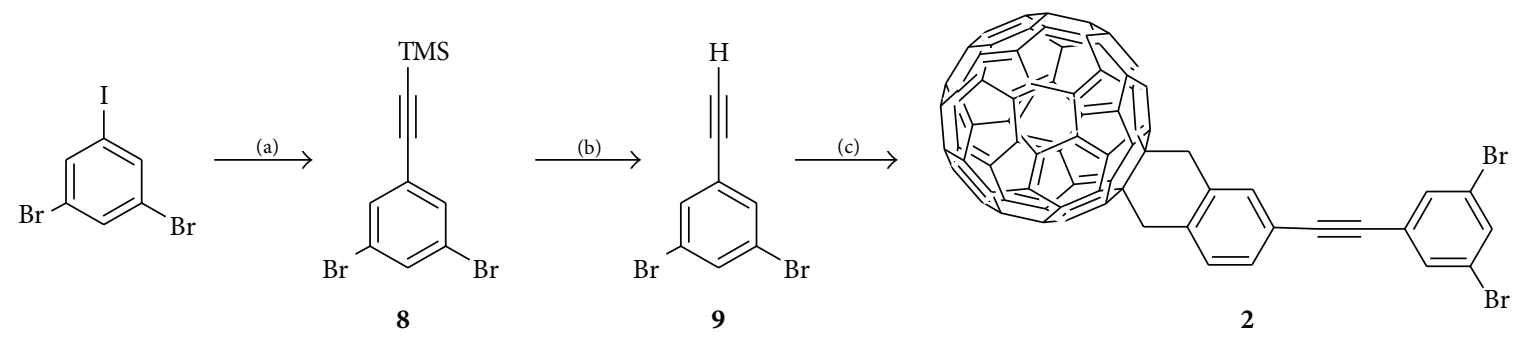

SCHEME 2: Synthesis of polymer repeat 2. Reaction conditions: (a) palladium catalyst, $\mathrm{CuI}_{1} \mathrm{Et}_{3} \mathrm{~N}$, toluene, and TMS acetylene; (b) THF, NaOH, and $\mathrm{MeOH}$; (c) palladium catalyst, $\mathrm{CuI}, \mathrm{Et}_{3} \mathrm{~N}, 1$, and toluene.

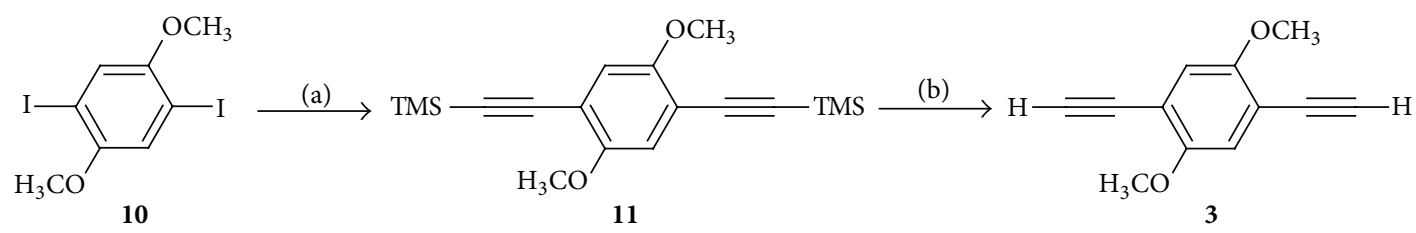

Scheme 3: Synthesis of polymer repeat 3. Reaction conditions: (a) palladium catalyst, $\mathrm{CuI}_{\mathrm{I}} \mathrm{Et}_{3} \mathrm{~N}$, toluene, and TMS acetylene; (b) THF, NaOH, and $\mathrm{MeOH}$.

in quantitative yield. ${ }^{1} \mathrm{H}$ NMR $\left(500 \mathrm{MHz} \mathrm{CDCl}_{3}\right) \delta 0.21(\mathrm{~s}$, $\left.\mathrm{CH}_{3}, 18 \mathrm{H}\right), 3.76$ (s, $\left.\mathrm{OCH}_{3}, 6 \mathrm{H}\right), 6.86$ (s, Ph, 2H).

2.6. Deprotection of $\mathbf{1 1}$ (3). In a $250 \mathrm{~mL}$ round bottom flask equipped with a stir bar, $11(0.0694 \mathrm{~g}, 0.2099 \mathrm{mmol}), 11.6 \mathrm{~mL}$ distilled THF, $3.6 \mathrm{~mL}$ of $20 \%(\mathrm{w} / \mathrm{v}) \mathrm{NaOH}$ solution, and $21.7 \mathrm{~mL}$ of methanol were added. The solution was stirred vigorously for 2 hours at room temperature, producing a clear solution. Once the stirring was complete, $50 \mathrm{~mL}$ of water and $40 \mathrm{~mL}$ of chloroform were added to the flask producing a white precipitate. The precipitate was removed via filtration, and the filtrate was placed in a separatory funnel. The organic layer was collected and dried with sodium sulfate. Removal of the solvent produced crude product 3 as a light brownish/yellow solid. The crude product was purified via MPLC on silica. The product eluted at $92: 8$ hexanes : ethyl acetate, $34 \%$ yield. ${ }^{1} \mathrm{H}$ NMR $\left(500 \mathrm{MHz} \mathrm{CDCl}_{3}\right) \delta 3.39$ (s, acetylene, 2H), $3.80\left(\mathrm{~s}, \mathrm{OCH}_{3}, 6 \mathrm{H}\right), 6.96$ (s, Ph, 2H).

2.7. Polymerization of 2 and 3 (5). In a $100.0 \mathrm{~mL}$ Schlenk flask equipped with a stir bar, $2(0.0583 \mathrm{~g}, 0.0538 \mathrm{mmol})$, $3(0.0100 \mathrm{~g}, 0.0538 \mathrm{mmol}), \quad \mathrm{PdCl}_{2}\left(\mathrm{PPh}_{3}\right)_{2} \quad$ (0.00189 g, $0.00267 \mathrm{mmol})$, and CuI $(0.000500 \mathrm{~g}, 0.00267 \mathrm{mmol})$ were added. This flask was connected to a condenser and then purged and filled with argon. Through the sidearm of the flask, $5.00 \mathrm{~mL}$ of distilled triethylamine and $14.0 \mathrm{~mL}$ of distilled THF were added via a purged and filled syringe. The flask was lowered into a $70^{\circ} \mathrm{C}$ oil bath and stirred for 24 hours. Following completion, the solvent was removed via rotary evaporation to produce a brownish/orange oily solid, polymer $\mathbf{5}$. This solid was sequentially extracted with hot acetone and hexanes, and solids were rotovapped from each wash. The remaining solid $(25 \mathrm{mg})$, acetone extraction $(15.9 \mathrm{mg})$, and hexanes extraction $(18.9 \mathrm{mg})$ were analyzed via GPC. The product was found in the acetone wash. ${ }^{1} \mathrm{H}$
NMR (500 MHz, $\left.\mathrm{C}_{6} \mathrm{D}_{6}\right) \delta 3.70$ (s, Acetylene, 2H), 3.80 (s, $\left.\mathrm{OCH}_{3}, 6 \mathrm{H}\right), 6.96$ (s, Ph, 2H), 3.89 (s, $\left.\mathrm{CH}_{2}, 2 \mathrm{H}\right), 3.91$ (s, $\mathrm{CH}_{2}$, $2 \mathrm{H})$.

2.8. Polymerization of 2 and $\mathbf{4}$ (6). In a $100.0 \mathrm{~mL} \mathrm{Schlenk}$ flask equipped with a stir bar, $2(0.0950 \mathrm{~g}, 0.0876 \mathrm{mmol})$, $4 \quad(0.0135 \mathrm{~g}, \quad 0.0876 \mathrm{mmol}), \quad \mathrm{PdCl}_{2}\left(\mathrm{PPh}_{3}\right)_{2} \quad(0.00307 \mathrm{~g}$, $0.00438 \mathrm{mmol})$, and $\mathrm{CuI}(0.000834 \mathrm{~g}, 0.00438 \mathrm{mmol})$ were added. This flask was connected to a condenser and then purged and filled with argon. Through the sidearm of the flask, $5.00 \mathrm{~mL}$ of distilled triethylamine and $14.0 \mathrm{~mL}$ of distilled THF were added via a purged and filled airtight syringe. The flask was lowered into a $70^{\circ} \mathrm{C}$ oil bath and stirred for 21 hours. Following completion, the solvent was removed via rotary evaporation to produce a brownish/orange oily solid, polymer $\mathbf{6}$. The solid was sequentially extracted with hot acetone and hexanes, and solids were rotovapped from each wash. The remaining solid following extractions was purified further via MPLC on silica. The purified product was eluted at 73:27 hexanes: ethyl acetate. The purified product and hexane wash were further analyzed via GPC.

2.9. Polymerization of $\mathbf{4}$ and $\mathbf{1 0}$ (7). In a $100.0 \mathrm{~mL}$ Schlenk flask equipped with a stir bar, $10(0.0109 \mathrm{~g}, 0.0279 \mathrm{mmol})$, $4(0.00430 \mathrm{~g}, 0.0279 \mathrm{mmol}), \mathrm{PdCl}_{2}\left(\mathrm{PPh}_{3}\right)_{2} \quad(0.00100 \mathrm{~g}$, $0.00140 \mathrm{mmol})$, and $\mathrm{CuI}(0.00030 \mathrm{~g}, 0.00140 \mathrm{mmol})$ were added. This flask was connected to a condenser and then purged and filled with argon. Through the sidearm of the flask, $5.00 \mathrm{~mL}$ of distilled triethylamine and $14.0 \mathrm{~mL}$ of distilled THF were added via a purged and filled syringe. The flask was lowered into an $80^{\circ} \mathrm{C}$ oil bath and stirred for 20 hours. Following completion, the solvent was removed via rotary evaporation to produce a dark brown solid, polymer 7. The solid was washed with $10 \mathrm{~mL}$ of ethyl acetate and sonication for 5 minutes and then filtered and washed with 


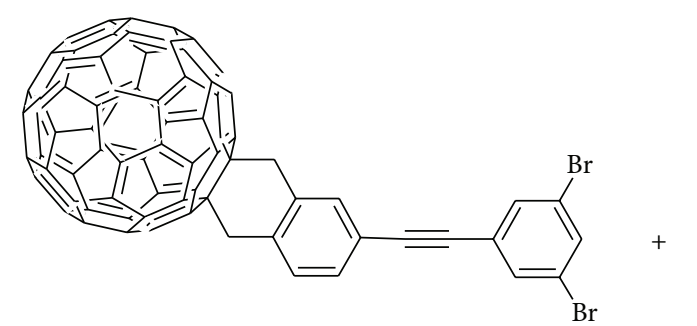

2

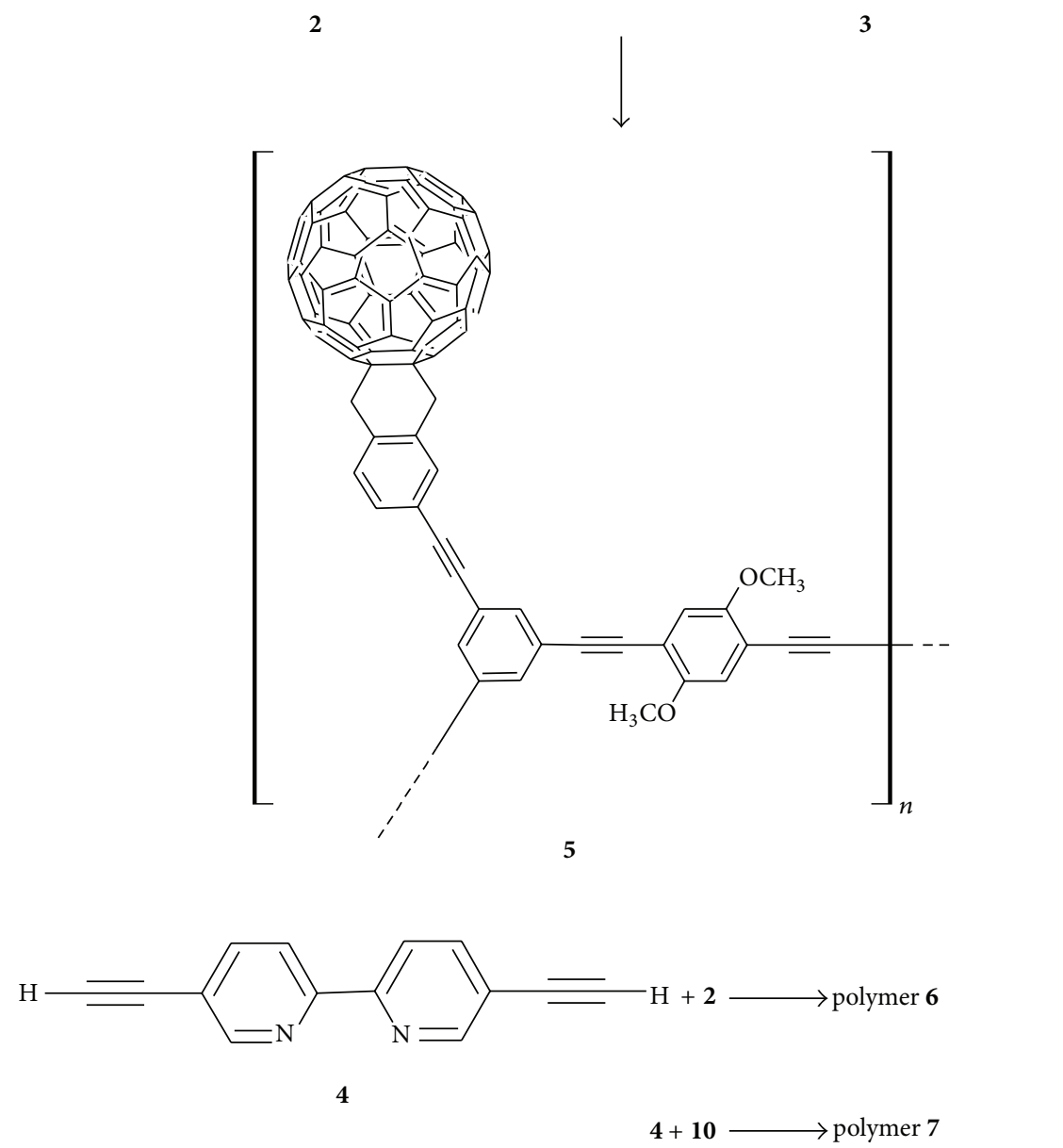<smiles>C#Cc1cc(OC)c(OC)cc1C#C</smiles>

SCHEME 4: Synthesis of polymers 5-7. General reaction conditions: palladium catalyst, CuI, Et ${ }_{3} \mathrm{~N}$, and THF.

additional ethyl acetate. The resulting product was further analyzed via GPC.

2.10. Gel Permeation Chromatography (GPC). A GPC System consisting of a 1525 Binary Pump, 717 Autosampler, 2414 Refractive Index (RI) detector, and a 2996 Photodiode Array (PDA) detector (Waters Corporation, Milford, MA, USA) was utilized in examining the polymer samples as indicated above. Due to backpressure limitations the RI detector was in series after the PDA detector. The mobile phase consisted of an isocratic mobile phase of tetrahydrofuran (THF) at a flow of $1 \mathrm{~mL} / \mathrm{min}$ with the analysis done on a Styragel HR 1 column $(7.8 \times 300 \mathrm{~mm}$, also from Waters Corporation) maintained at a temperature of $50^{\circ} \mathrm{C}$ in a column oven. Control of the equipment was done using the Empower 3 software with the GPC option for calibration and data handling (also

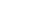

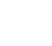


TABLE 1: GPC data on polymers 5-7.

\begin{tabular}{lccc}
\hline Polymer & $M_{\mathrm{w}} / \mathrm{kD}$ & $M_{\mathrm{w}}$ (corrected) $/ \mathrm{kD}$ & Repeat units \\
\hline $\mathbf{5}$ & 12.81 & 41.66 & 32.7 \\
$\mathbf{6}$ & 12.44 & 42.96 & 34.7 \\
$\mathbf{7}$ & 14.29 & N/A & 47.5 \\
\hline
\end{tabular}

purification needed. Indeed, the most challenging step is the final attachment of substituted fullerene 1 , due both to the poor solubility of the modified fullerene in the necessary solvents for these coupling reactions and to a significant side product where the substituted aromatic preferentially reacts with itself. Once the repeat units were available, the polymerization was relatively straightforward and provided welldefined PPE-type polymers based on their limited reaction sites. Not surprisingly, the polymeric products precipitated out of solution during the reaction period, again due to the poor fullerene solubility. This solubility issue is a likely cause for the lower than desired molecular weights for these products (vide infra). The obtained polymers exhibited different physical properties and greatly broadened NMR features compared to their monomeric precursors. Initial spectroscopic examination did demonstrate that unreacted monomers were present in the crude products. Through experimentation with different washes and extractions, it was determined that the desired polymer products containing fullerenes (5 and 6) were preferentially removed with a hot acetone extraction over more polar solvents that generally removed unreacted monomers. Polymer 7 is very similar in structure to a previously reported polymer [40], but with shorter side chains on the dialkoxy benzene unit. Its physical and spectroscopic characteristics are very similar to this previously reported system.

3.2. GPC Characterization. The use of GPC to determine molecular weights of fullerene-containing compounds has been performed previously using polystyrene standards and RI detection [26, 27, 41-45]. In our case, the addition of PDA detection allowed for peak identification of the compounds of interest based upon their UV-Visible absorption spectra (since the chromophore absorption spectrum stays relatively consistent before and after polymerization, vide infra) and the corresponding RI peak used for molecular weight determination. The GPC results showed relatively monodisperse samples, but the obtained molecular weights were much lower than expected (Table 1) when compared to the polystyrene standards. This disparity stems from fullerene's size in relation to the packing material pore size. Instead of the normal interaction expected between the analyte molecules and packing material, the large diameter of the fullerene prevents this interaction, thus altering the expected retention time of the analyte. Hence, the polymer portions associated with the PPE backbone may interact with the media, but the fullerene portion is effectively ignored. While several researchers have successfully utilized GPC for fullerene-containing polymers without issue [27, 43, 44], many of these systems have significantly more limited fullerene loading than our structures. However, other groups

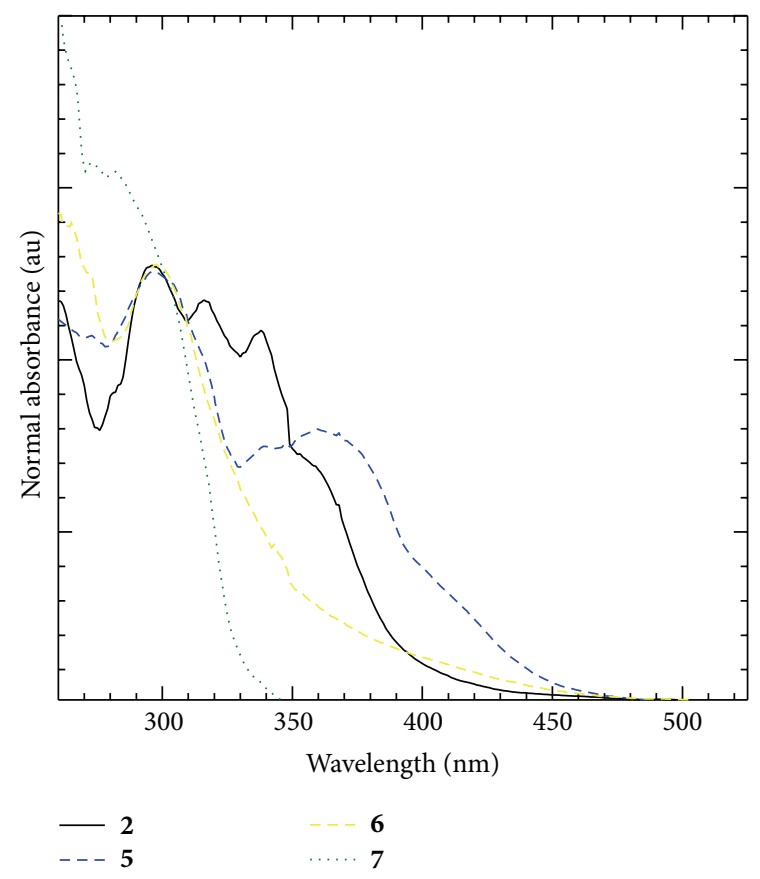

FIGURE 1: Normalized absorption spectra (at $300 \mathrm{~nm}$ ) recorded on degassed 2-MTHF solutions of polymer subunit $\mathbf{2}$ and polymers 57.

$[26,45]$ have reported large disparities between their GPC results and independent molecular weight determinations for the same reason described above. Although more sophisticated corrections were applied in these studies, we can apply a simple ratio assuming that the PPE mass is the sole portion of the polymer represented by the GPC data (i.e., apply a ratio of the PPE backbone's portion of the utilized repeat unit to the obtained molecular weight values). Following correction, the molecular weight increases significantly (Table 1) and represents between 30 and 40 repeat units for each polymer sample. For polymer 7, the obtained molecular weight did not need correction (since fullerene is not present) and was similar to previously reported PPE polymers with similar structure [40] and in the range of our other samples. Polymer $\mathbf{7}$ had a higher number of repeat units obtained than $\mathbf{5}$ and 6, which is not surprising considering the solubility issues of the substituted fullerene (vide supra) that restricted the polymerization reaction times before product precipitation.

3.3. UV-Vis Absorption Spectroscopy. Absorption spectra of precursor 2 and polymers 5-7 in 2-MTHF at optically dilute concentrations are shown in Figure 1. For the fullerenecontaining precursor, the spectrum is very similar to previously reported substituted fullerene $1[4,6]$ with intense absorption bands below $350 \mathrm{~nm}$ typically associated with aromatic $\pi, \pi^{*}$ transitions $[1,46-50]$. We do not observe the longer wavelength features typically associated with fullerenes, likely due to the intense absorption associated with the aromatic "hub" structure. Upon polymerization, fullerene-containing polymers $\mathbf{5}$ and $\mathbf{6}$ retain the major 

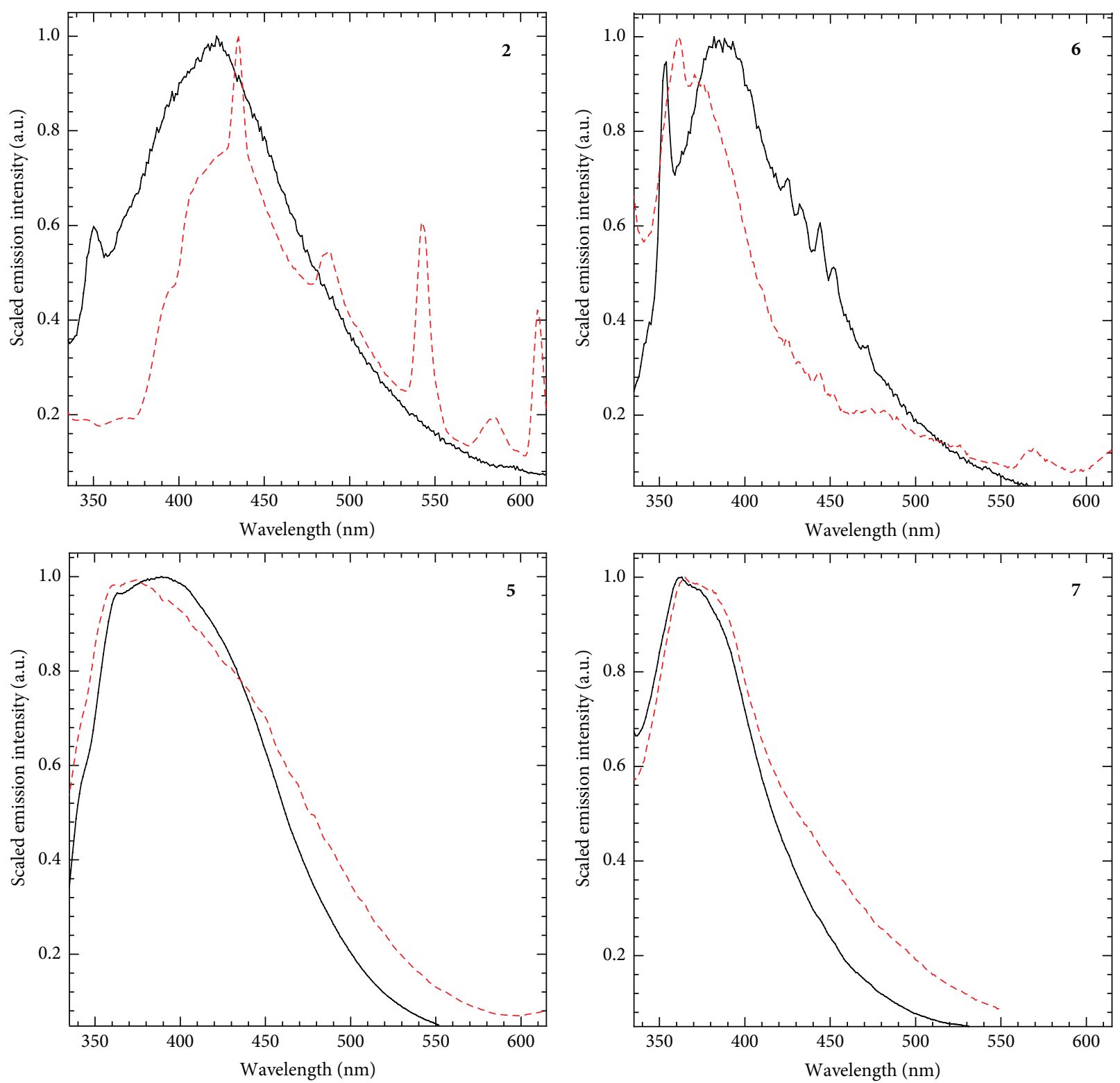

Figure 2: Normalized emission spectra recorded on degassed 2-MTHF solutions at $298 \mathrm{~K}$ (solid) and $80 \mathrm{~K}$ (dashed), excitation wavelength $320 \mathrm{~nm}$. Emission intensity decreases (except 2) with reduced temperature.

absorption around $300 \mathrm{~nm}$ but exhibit some of the characteristic changes in absorption spectra typically seen in polymers as excited states shift to lower, potentially more complicated energy manifolds (e.g., red-shifting of bands, band broadening, and tailing to longer wavelengths). These changes are particularly apparent in polymer $\mathbf{5}$ that contains the fullerene and benzene moieties. The effect is less pronounced in polymer 6 that contains fullerene and bipyridine moieties due to the potential of the bipyridine to twist (vide infra), but the spectra are consistent with our small molecule studies [6] that indicated the large absorption cross section of the fullerene dominates the excitation profile of the system. Only the higher energy aromatic absorption is retained in polymer 7, which is similar to previously reported systems [51]. Since 7 does not contain the fullerene moiety, we can assign the redder features to this portion of the polymers and any possible charge transfer states between the polymer backbone and pendant fullerenes. The absorption tails to lower energies present in these dilute solutions suggest some aggregation of the polymer strands (vide infra) [52].

3.4. Emission Spectroscopy. Emission spectra for precursor 2 and polymers 5-7 in degassed 2-MTHF at 298 and $80 \mathrm{~K}$ are shown in Figure 2. Molecules were excited at $320 \mathrm{~nm}$, which focused on the higher energy bands observed in the absorption spectrum (vide supra). Emission at $298 \mathrm{~K}$ is generally dominated by the presence of a strong, relatively broad peak between 370 and $400 \mathrm{~nm}$ depending on the sample. For precursor 2 , this peak can be assigned to ${ }^{1} \pi, \pi^{*}$ fluorescence due to interaction between the fullerene and 
aromatic "hub" (vide infra) and is similar to our previously reported substituted fullerene systems. We do not see any long wavelength emission at room temperature commonly observed for unsubstituted fullerene. Emission spectra are generally expected to broaden when comparing monomers to their ensuing polymers, but this broadening is minimal with these systems (e.g., cf. 2 and 5-7). This result can be explained by the already broad emission of the substituted fullerene in $\mathbf{2}$ coupled with the observed presence of intermolecular aggregation (vide infra). The polymer spectra appear to exhibit two overlapping peaks: around $360 \mathrm{~nm}$ that corresponds to the PPE backbone (both bipyridine and dialkoxy repeat units) and around $400 \mathrm{~nm}$ that corresponds to the substituted fullerene moiety. This assignment aligns well with the data obtained for 7 , since only the single higher energy peak is observed in this polymer. Interestingly, the difference in PPE backbone between $\mathbf{5}$ and $\mathbf{6}$ manifested in their emission spectra is more pronounced than expected. The narrow, blue-shifted emission for $\mathbf{6}$ is likely due to the locked orthogonal twist between rings in the bipyridine moiety in the solvent glass, significantly reducing the effective conjugation of the system and raising the excited-state energy. While this twist has been observed in other PPE polymers [52], it is more pronounced here due to the large bulk of the pendent fullerenes that further reduce the likelihood of bipyridine planarity.

Upon cooling, the observed fluorescence decreases in intensity (except for $\mathbf{2}$, which increases) and exhibits some red-shifting. The additional peak structure seen for subunit $\mathbf{2}$ is similar to substituted fullerene $\mathbf{1}$ as previously reported, which is typical of fullerene emission from a $\pi, \pi^{*}$ excited state [46, 47]. However, the fullerene-like emission characteristics are largely absent from polymers $\mathbf{5}$ and $\mathbf{6}$ at $80 \mathrm{~K}$. Instead, the polymers respond much like other PPE-type polymers, suggesting that the backbone provides the predominant deactivation pathway for the excited-state manifold (vide infra).

While the intensity decrease upon reduced temperature may be due to the presence of accessible dark deactivation pathways, the more likely explanation is intermolecular deactivation due to aggregation of the polymeric strands [52]. We were able to detect significant depolarization of the emission signal at reduced temperatures for all polymer samples through the sharp decrease of anisotropy value $r(\lambda)$. This depolarization largely results from exciton migration between individual polymer strands upon photoexcitation. Such aggregation is even apparent at room temperature in optically dilute solutions for fullerene-containing polymers $\mathbf{5}$ and $\mathbf{6}$ (vide supra), with slight emission depolarization even at $298 \mathrm{~K}$ that becomes significantly pronounced at temperatures below $200 \mathrm{~K}$. Such depolarization has been observed for other PPE oligomeric and polymeric systems [52, 53], but these systems more easily associate due to the large size of the fullerenes and the absence of long alkyl side chains normally found in PPE systems to enhance solubility and discourage aggregation.

Emission lifetimes were recorded at $298 \mathrm{~K}$ and $80 \mathrm{~K}$ for precursor $\mathbf{2}$ and polymers 5-7 and are listed in Table 2. Emission lifetimes were similar at various wavelengths sampled
TABLE 2: Emission lifetime data on repeat unit 2 and polymers $5-7^{\mathrm{a}}$.

\begin{tabular}{lcc}
\hline Compound & $\tau(298 \mathrm{~K}) / \mathrm{ns}$ & $\tau(80 \mathrm{~K}) / \mathrm{ns}$ \\
\hline $\mathbf{2}$ & 24.1 & 25.9 \\
$\mathbf{5}$ & 21.6 & 18.3 \\
$\mathbf{6}$ & 27.8 & 24.7 \\
$\mathbf{7}$ & $11.5^{\mathrm{b}}$ & $16.4^{\mathrm{b}}$ \\
\hline
\end{tabular}

${ }^{a}$ Data recorded on degassed 2-MTHF solutions, $355 \mathrm{~nm}$ excitation, $425 \mathrm{~nm}$ emission. ${ }^{\mathrm{b}}$ Limited by the pulse width of excitation laser (10 ns), likely shorter.

across the observed emission manifold, and decays were fit by a single exponential model. It should be noted that the measured lifetime for 7 is approaching the FWHM of our excitation laser $(10 \mathrm{~ns})$, suggesting that the lifetime is likely shorter than recorded (similar PPE-type polymer samples typically have fluorescence lifetimes around $1 \mathrm{~ns})[40,54-$ 56]. The fullerene-containing samples have distinctly longer lifetimes than 7 but are still relatively short. Previously, we observed $425 \mathrm{~nm}$ emission lifetimes for $\mathbf{1}$ and 1-bipyridine dyads around $150 \mathrm{~ns}$ that slightly decreased to ca. $100 \mathrm{~ns}$ upon cooling [6]. Instead, a significantly shorter lifetime is observed for these samples at room temperature. The decrease in lifetimes is not entirely surprising, as the presumed aggregation of the polymer strands (vide supra) could provide additional excited-state deactivation pathways not present in the small molecule analogs. In addition, the lack of fullerene spectral signatures in the emission (vide supra) normally seen in the small molecule analogs provides further evidence of a perturbed excited-state manifold as a result of the polymerization.

3.5. Excited-State Behavior. To better understand the structure of the excited-state manifold of these systems, we have constructed the Jablonski diagram shown in Scheme 5. We have reported a similar structure for our fullerene-bipyridine small molecule systems [6], with one key difference as noted in Scheme 5. Polymer 7 (without fullerene present) provides the typical excited-state behavior normally seen for PPE-based polymers, with a pronounced fluorescence from a ${ }^{1} \pi, \pi^{*}$ excited state. Previous work also indicates that a nonemissive ${ }^{3} \pi, \pi^{*}$ state provides an alternative decay pathway. The fluorescence lifetimes are short (likely shorter than reported; vide supra), corresponding to that expected in these systems.

The excited-state behavior exhibited by monomer 2 is similar to monomer $\mathbf{1}$ as reported before. In $\mathbf{2}$ a similar fluorescence is seen that is dominated by a ${ }^{1} \pi, \pi^{*}$ excited state at lower energy than that seen for polymer 7. Any evidence of a lower-energy fullerene-based ${ }^{3} \pi, \pi^{*}$ excited state $(1.50 \mathrm{eV})$ [57] is only observed at lower temperatures as a red-shifted emission, suggesting the singlet state is strongly coupled to the ground state. This singlet energy level does not correspond well to either the unsubstituted fullerene (much lower) or aromatic "handle" (somewhat higher) portions, suggesting significant interaction between these two moieties to produce a delocalized state. Indeed, computational studies [10] on our small molecule analogs of these systems clearly 

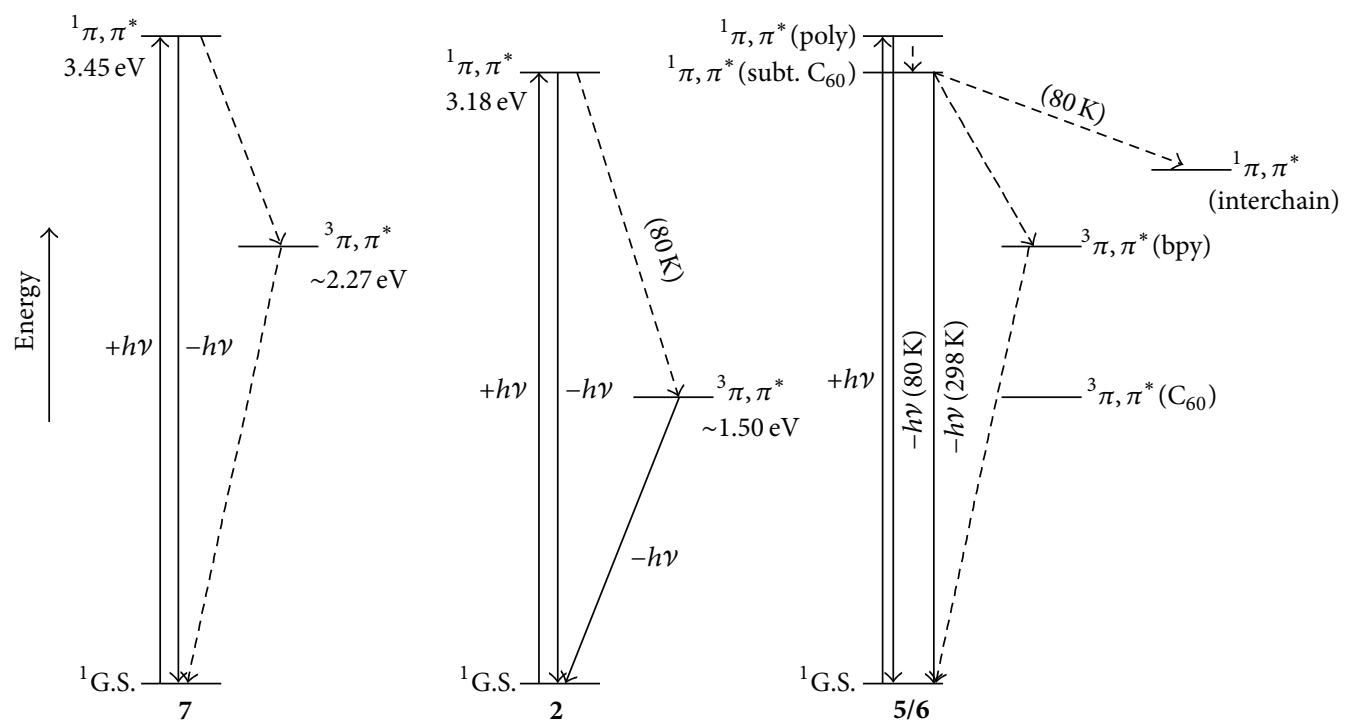

SCHEME 5: Jablonski diagram of monomer 2 and polymers 5-7.

illustrate the extended delocalization within the substituted fullerene system. This delocalization also produces the modestly increased (but still relatively short) lifetimes. Recent studies utilizing Stark absorption spectroscopy on these systems provide additional support that the accessed ${ }^{1} \pi, \pi^{*}$ state associated with the substituted fullerene is centered on the organic "hub" portion of the moiety. Key to this analysis is the treatment of the substituted fullerene/benzene hub moiety as a single unit that is dominated by a higher energy ${ }^{1} \pi, \pi^{*}$ transition, rather than the fullerene exhibiting excitedstate behavior separate from the attached organic framework. It is possible that these systems exhibit excited-state behavior centered on the fullerene (ca. short emission lifetimes), but such rapid emission decay would not be observable with our current instrumentation due to our excitation laser's FWHM (vide supra). Interestingly, the ${ }^{1} \pi, \pi^{*}$ state for $\mathbf{2}$ is lower than $\mathbf{1}$, presumably due to the extended organic framework following substitution to the trisubstituted benzene ring.

Turning to fullerene-containing polymers 5 and $\mathbf{6}$, the relative isolation of the substituted fullerene moiety from the polymer backbone leads to independent behavior of these two subunits as demonstrated by the clear presence of two overlapping emission peaks in the $298 \mathrm{~K}$ data of $\mathbf{5}$ and $\mathbf{6}$. These peaks align well with those independently observed for the fullerene/hub and polymer backbone in 2 and 7, respectively. Because the substituted fullerene moiety is lower in energy than the polymer backbone, we expect the majority of the excited-state decay moves through this state since the emission lifetimes remain relatively constant among 2,5 , and 6. The contribution of the polymer backbone excited state is overemphasized in the emission spectrum due to the high fluorescence quantum yield of organic PPE-based polymers.

Upon cooling, only the polymer backbone fluorescence remains (e.g., cf. the $80 \mathrm{~K}$ emissions of $\mathbf{2}$ and 5), suggesting the substituted fullerene moiety is deactivated through a different nonemissive state (the phosphorescence seen for 2 at low temperatures is not observed). Based on the decreased emission anisotropy values observed at low temperature (vide supra), we believe this state instead exhibits interchain energy transfer, leaving the polymer backbone-based state to radiatively decay. Unlike other studies that show a loss of emission upon aggregation [52], the large size of the fullerenes and their relative isolation from the polymer backbone electronics allow them to effectively buffer the polymer from any interchain deactivation effects. A recent report by $\mathrm{Li}$ and Benicewicz [28] suggests that polymers with pendant fullerenes aggregate readily, so our anisotropy results are not surprising. However, we are not aware of such a derivatized polymer insulating the core system from interchain energy transfer deactivation. The emission lifetime slightly decreases for polymers $\mathbf{5}$ and $\mathbf{6}$ at reduced temperatures, which also supports the conclusion that the polymer backbone excited state becomes the primary mode of decay. It does not completely decrease to that observed for 7 , presumably due to lingering aggregation effects or measurement uncertainty due to the short lifetimes for our instrumentation (vide supra).

\section{Conclusion}

Our group has adapted our methodologies for provided substituted fullerenes in order to integrate them into polymeric repeat units. Polymer molecular weights were confirmed using GPC, taking into account the large size of the fullerenes and their likely incompatibility with the column packing material. Spectroscopic absorption and emission data suggest the presence of excited states associated with both the substituted fullerene and polymer backbone portions and that these excited states are relatively isolated. The polymeric systems also exhibit aggregation even at modest optical densities and at higher temperatures than other PPEbased systems, which is also exhibited in the absence of the substituted fullerene excited state at reduced temperatures (while the isolated backbone fluorescence is still seen). The synthetic strategies reported here can be used to design 
other oligomeric and polymeric systems containing extended polyaromatic structures (e.g., corannulene and coronene incorporation are currently being explored by our group). Future efforts also involve improving the molecular weight of these polymeric systems through methodology modification (e.g., solvent usage that is more amenable to fullerenes), the ligation of transition metal chromophores to the bipyridine subunits, and further probing of the excited-state behavior with transient absorption spectroscopy and Stark absorption spectroscopy.

\section{Conflict of Interests}

The authors declare that there is no conflict of interests regarding the publication of this paper.

\section{Acknowledgments}

The authors thank the National Science Foundation (Grants CHE-0904306 and CHE-1306932), the NKU Research Foundation, the NKU Department of Chemistry, and the NKU Center for the Integration of Science and Mathematics for financial and logistical support. The authors would also like to thank Waters Corporation for continued support of research at Northern Kentucky University and for the loan of the 2414 Refractive Index detector for this research.

\section{References}

[1] H. D. Lee, S. K. Oh, C. S. Choi, and K. Kay, "A novel amphiphilic reI complex with Bis(fullerene)-substituted bipyridine ligands: synthesis, electrochemistry, and langmuir film," European Journal of Inorganic Chemistry, vol. 2007, no. 4, pp. 503-508, 2007.

[2] J. D. Megiatto Jr., D. I. Schuster, S. Abwandner, G. De Miguel, and D. M. Guldi, "[2]Catenanes decorated with porphyrin and fullerene groups: design, convergent synthesis, and photoinduced processes," Journal of the American Chemical Society, vol. 132, no. 11, pp. 3847-3861, 2010.

[3] A. D. Darwish, "Fullerenes," Annual Reports on the Progress of Chemistry Section A: Inorganic Chemistry, vol. 103, pp. 370-391, 2007.

[4] J. R. Deye, A. N. Shiveley, S. M. Goins, L. Rizzo, S. A. Oehrle, and K. A. Walters, "Synthesis of a new ligand for transition metalfullerene supramolecular systems," Inorganic Chemistry, vol. 47, no. 1, pp. 23-25, 2008.

[5] J. Deye and K. A. Walters, "Synthesis of a novel fullerenebipyridine ligand for photoelectric applications," in Proceedings of the 39th Central Regional Meeting of the American Chemical Society, CRM-096, Covington, Ky, USA, May 2007.

[6] E. A. Walsh, J. R. Deye, W. Baas, K. Sullivan, A. Lancaster, and K. A. Walters, "Synthesis and spectroscopic studies of transitionmetal fullerene supramolecular systems," Journal of Photochemistry and Photobiology A: Chemistry, vol. 260, pp. 24-36, 2013.

[7] A. Juris, V. Balzani, F. Barigelletti, S. Campagna, P. Belser, and A. von Zelewsky, "Ru(II) polypyridine complexes: photophysics, photochemistry, eletrochemistry, and chemiluminescence," Coordination Chemistry Reviews, vol. 84, pp. 85-277, 1988.

[8] J. A. Clark, M. M. Richter, K. J. Brewer, D. Seniveratne, and J. F. Endicott, "Syntheses of selected supramolecules.
Supramolecular complexes of bis(2,2I-bipyridine)osmium(II) and ruthenium(II)," in Inorganic Syntheses, vol. 33, pp. 26-39, 2002.

[9] L. Worl, R. Duesing, P. Chen, L. D. Ciana, and T. J. Meyer, "Photophysical properties of polypyridyl carbonyl complexes of rhenium(I)," Journal of the Chemical Society, Dalton Transactions, vol. 1991, pp. 849-858, 1991.

[10] M. Darvish Ganji, M. Shokri, R. Alizadeh, and M. Khademaboulfazli, "Structural and electronic properties of supramolecular $\mathrm{C}_{60}: \mathrm{RU}(\mathrm{II})\left(\right.$ bipy) ${ }_{3}: \mathrm{C}_{60}$ triad: $\mathrm{Ab}$ initio van der Waals calculations," Physica E: Low-dimensional Systems and Nanostructures, vol. 69, pp. 384-393, 2015.

[11] K. K.-W. Lo, "Exploitation of luminescent organometallic rhenium(I) and iridium(III) complexes in biological studies," Topics in Organometallic Chemistry, vol. 29, pp. 115-158, 2010.

[12] B. Happ, A. Winter, M. D. Hager, and U. S. Schubert, "Photogenerated avenues in macromolecules containing $\operatorname{Re}(\mathrm{I}), \mathrm{Ru}(\mathrm{II})$, Os(II), and Ir(III) metal complexes of pyridine-based ligands," Chemical Society Reviews, vol. 41, no. 6, pp. 2222-2255, 2012.

[13] C. J. P. Monteiro, M. M. Pereira, M. G. H. Vicente, and L. G. Arnaut, "Photophysical properties of unsymmetric mesosubstituted porphyrins synthesized via the Suzuki coupling reaction," Tetrahedron, vol. 68, no. 42, pp. 8783-8788, 2012.

[14] C. Coluccini, N. Manfredi, M. M. Salamone et al., "Quaterpyridine ligands for panchromatic $\mathrm{Ru}(\mathrm{II})$ dye sensitizers," Journal of Organic Chemistry, vol. 77, no. 18, pp. 7945-7956, 2012.

[15] R. Matassa, I. Fratoddi, M. Rossi, C. Battocchio, R. Caminiti, and M. V. Russo, "Two-dimensional networks of Ag nanoparticles bridged by organometallic ligand," Journal of Physical Chemistry C, vol. 116, no. 29, pp. 15795-15800, 2012.

[16] J. Wang, S. Arachchige, and K. J. Brewer, "Supramolecular complex design and function for photodynamic therapy and solar energy conversion via hydrogen production: common requirements for molecular architectures for varied light-activated processes," in Applications of Supramolecular Chemistry, pp. 255-300, CRC Press, 2012.

[17] S. A. Backer, K. Sivula, D. F. Kavulak, and J. M. J. Fréchet, "High efficiency organic photovoltaics incorporating a new family of soluble fullerene derivatives," Chemistry of Materials, vol. 19, no. 12, pp. 2927-2929, 2007.

[18] F. Giacalone and N. Martín, "Fullerene polymers: synthesis and properties," Chemical Reviews, vol. 106, no. 12, pp. 5136-5190, 2006.

[19] W. C. Tsoi, D. T. James, E. B. Domingo et al., "Effects of a heavy atom on molecular order and morphology in conjugated polymer:fullerene photovoltaic blend thin films and devices," ACS Nano, vol. 6, no. 11, pp. 9646-9656, 2012.

[20] A. J. Ferguson, J. L. Blackburn, and N. Kopidakis, "Fullerenes and carbon nanotubes as acceptor materials in organic photovoltaics," Materials Letters, vol. 90, pp. 115-125, 2013.

[21] N. C. Miller, E. Cho, R. Gysel et al., "Factors governing intercalation of fullerenes and other small molecules between the side chains of semiconducting polymers used in solar cells," Advanced Energy Materials, vol. 2, no. 10, pp. 1208-1217, 2012.

[22] M. Nakaya, Y. Okawa, C. Joachim, M. Aono, and T. Nakayama, "Nanojunction between fullerene and one-dimensional conductive polymer on solid surfaces," ACS Nano, vol. 8, no. 12, pp. 12259-12264, 2014.

[23] S. K. Hau, Y.-J. Cheng, H.-L. Yip, Y. Zhang, H. Ma, and A. K.Y. Jen, "Effect of chemical modification of fullerene-based selfassembled monolayers on the performance of inverted polymer 
solar cells," ACS Applied Materials and Interfaces, vol. 2, no. 7, pp. 1892-1902, 2010.

[24] P. Cavigli, T. Da Ros, A. Kahnt, M. Gamberoni, M. T. Indelli, and E. Iengo, "Zinc porphyrin-Re(I) bipyridyl-fullerene triad: synthesis, characterization, and kinetics of the stepwise electrontransfer processes initiated by visible excitation," Inorganic Chemistry, vol. 54, no. 1, pp. 280-292, 2015.

[25] S. Lu, W. Si, M. Bao, Y. Yamamoto, and T. Jin, "Co-catalyzed radical cycloaddition of [60]fullerene with active dibromides: selective synthesis of carbocycle-fused fullerene monoadducts," Organic Letters, vol. 15, no. 15, pp. 4030-4033, 2013.

[26] R. C. Hiorns, E. Cloutet, E. Ibarboure et al., "Main-chain fullerene polymers for photovoltaic devices," Macromolecules, vol. 42, no. 10, pp. 3549-3558, 2009.

[27] R. Katiyar, D. S. Bag, and I. Nigam, "Copolymerization of fullerene (C60) and methyl methacrylate (MMA) using triphenylbismuthonium ylide as a novel initiator and characterization of the copolymers (C60-MMA)," Journal of Macromolecular Science, Part A: Pure and Applied Chemistry, vol. 47, no. 5, pp. 468-477, 2010.

[28] J. Li and B. C. Benicewicz, "Synthesis of well-defined side chain fullerene polymers and study of their self-aggregation behaviors," Journal of Polymer Science Part A: Polymer Chemistry, vol. 51, no. 17, pp. 3572-3582, 2013.

[29] W.-B. Zhang, Y. Tu, R. Ranjan et al., “'Clicking’ fullerene with polymers: synthesis of [60]fullerene end-capped polystyrene," Macromolecules, vol. 41, no. 3, pp. 515-517, 2008.

[30] S. Ueda, K. Ohno, Y. Noguchi, S. Ishii, and J. Onoe, "Dimensional dependence of electronic structure of fullerene polymers," Journal of Physical Chemistry B, vol. 110, no. 45, pp. 22374-22381, 2006.

[31] K. Kokubo, R. Takahashi, M. Kato, A. Harada, T. Noguchi, and T. Oshima, "Thermal and thermo-oxidative stability of thermoplastic polymer nanocomposites with arylated [60]fullerene derivatives," Polymer Composites, 2014.

[32] D. V. Konarev, S. S. Khasanov, Y. Nakano et al., "Linear coordination fullerene $\mathrm{C}_{60}$ polymer $\left[\mathrm{Ni}\left(\mathrm{Me}_{3} \mathrm{P}\right)_{2}\left(\mu-\eta^{2}, \eta^{2}-\mathrm{C}_{60}\right)\right]_{\infty}$ bridged by zerovalent nickel atoms," Inorganic Chemistry, vol. 53, no. 22, pp. 11960-11965, 2014.

[33] A. Celli, P. Marchese, M. Vannini et al., "Synthesis of novel fullerene-functionalized polysulfones for optical limiting applications," Reactive and Functional Polymers, vol. 71, no. 6, pp. 641-647, 2011.

[34] M. L. Jia, Y. Wan, X. F. Wang, and A. D. Xia, "Photoinduced charge transfer in porphyrin-C60 oligomer," Science China Chemistry, vol. 53, no. 2, pp. 419-425, 2010.

[35] Y.-G. Ko, S. G. Hahm, K. Murata et al., "New fullerenebased polymers and their electrical memory characteristics," Macromolecules, vol. 47, no. 23, pp. 8154-8163, 2014.

[36] F. D’Souza, S. Gadde, D.-M. Shafiqul Islam et al., "Multitriphenylamine-substituted porphyrin-fullerene conjugates as charge stabilizing 'Antenna-Reaction Center' mimics,' Journal of Physical Chemistry A, vol. 111, no. 35, pp. 8552-8560, 2007.

[37] K. K. Chin, S.-C. Chuang, B. Hernandez, M. Selke, C. S. Foote, and M. A. Garcia-Garibay, "Photophysical properties of a 1,2,3,4,5,6-hexasubstituted fullerene derivative," Journal of Physical Chemistry A, vol. 110, no. 51, pp. 13662-13666, 2006.

[38] K. Sonogashira, "Coupling reactions between sp2 and Sp carbon centers," in Comprehensive Organic Synthesis, B. M. Trost and I. Fleming, Eds., vol. 3, p. 521, Pergamon Press, Oxford, UK, 1991.
[39] M. B. Ramey, Jeri'Annr, M. F. Rubner, C. Tan, K. S. Schanze, and J. R. Reynolds, "Amplified fluorescence quenching and electroluminescence of a cationic poly ( $p$-phenylene-co-thiophene) polyelectrolyte," Macromolecules, vol. 38, no. 2, pp. 234-243, 2005.

[40] K. D. Ley and K. S. Schanze, "Photophysics of metal-organic $\pi$ conjugated polymers," Coordination Chemistry Reviews, vol.171, pp. 287-307, 1998.

[41] J. H. Park, N. C. Kim, Y. T. Kim, S. W. Nam, Y. J. Kim, and J.-H. Kim, "Preparation and characteristics of poly(phenylene ether)s in various reaction conditions," Polymer, vol. 35, no. 3, pp. 244248, 2011.

[42] P. D. Barata, A. I. Costa, L. F. V. Ferreira, and J. V. Prata, "Synthesis, structure, and optical properties of an alternating calix[4]arene-based meta-linked phenylene ethynylene copolymer," Journal of Polymer Science Part A: Polymer Chemistry, vol. 48, no. 22, pp. 5040-5052, 2010.

[43] M. A. Lopatin, N. P. Evlampieva, T. I. Lopatina, Y. L. Kuznetsova, and P. N. Lavrenko, "Methyl methacrylate polymerization in the presence of $\mathrm{C}_{60}\left(\mathrm{C}_{70}\right)$ and molecular characteristics of fullerenecontaining poly(methyl methacrylate)," Russian Journal of General Chemistry, vol. 78, no. 8, pp. 1545-1552, 2008.

[44] M. Mehl, W. J. Pitz, S. M. Sarathy, and C. K. Westbrook, "Modeling the combustion of high molecular weight fuels by a functional group approach," International Journal of Chemical Kinetics, vol. 44, no. 4, pp. 257-276, 2012.

[45] K. Fu, Y. J. Zhang, Z. Guo, J. Wright, and Y.-P. Sun, "Gel permeation chromatography of fullerene-centered macromolecules," Journal of Chromatographic Science, vol. 42, no. 2, pp. 67-69, 2004.

[46] N. Armaroli, G. Accorsi, D. Felder, and J.-F. Nierengarten, "Photophysical properties of the ReI and RuII complexes of a new C60-substituted bipyridine ligand," Chemistry-A European Journal, vol. 8, no. 10, pp. 2314-2323, 2002.

[47] A. Kahnt, L.-P. Heiniger, S.-X. Liu et al., "An electrochemical and photophysical study of a covalently linked inorganicorganic dyad," ChemPhysChem, vol. 11, no. 3, pp. 651-658, 2010.

[48] A. Ramírez-Monroy and T. M. Swager, "Metal chelates based on isoxazoline[60]fullerenes," Organometallics, vol. 30, no. 9, pp. 2464-2467, 2011.

[49] E. Brunet, M. Alonso, M. C. Quintana, O. Juanes, and J.-C. Rodríguez-Ubis, "Facile synthesis of new fullerene-Ru(bpy) dyads bearing phosphonate groups for hybrid organicinorganic materials," Tetrahedron Letters, vol. 48, no. 21, pp. 3739-3743, 2007.

[50] Z. Zhou, G. H. Sarova, S. Zhang et al., "Fullerene polypyridine ligands: synthesis, ruthenium complexes, and electrochemical and photophysical properties," Chemistry - A European Journal, vol. 12, no. 16, pp. 4241-4248, 2006.

[51] K. D. Ley, Y. Li, J. V. Johnson, D. H. Powell, and K. S. Schanze, "Synthesis and characterization of $\pi$-conjugated oligomers that contain metal-to-ligand charge transfer chromophores," Chemical Communications, no. 17, pp. 1749-1750, 1999.

[52] K. A. Walters, K. D. Ley, and K. S. Schanze, "Photophysical consequences of conformation and aggregation in dilute solutions of $\pi$-conjugated oligomers," Langmuir, vol. 15 , no. 17, pp. 5676$5680,1999$.

[53] P. K. Lo and H. F. Sleiman, "Synthesis and molecular recognition of conjugated polymer with DNA-mimetic properties," Macromolecules, vol. 41, no. 15, pp. 5590-5603, 2008.

[54] T. L. Andrew and T. M. Swager, "Structure property relationships for exciton transfer in conjugated polymers," NATO 
Science for Peace and Security Series B: Physics and Biophysics, pp. 215-250, 2013.

[55] E. L. Dane, S. B. King, and T. M. Swager, "Conjugated polymers that respond to oxidation with increased emission," Journal of the American Chemical Society, vol. 132, no. 22, pp. 7758-7768, 2010.

[56] C. Y.-S. Chung and V. W.-W. Yam, "Induced self-assembly and Förster resonance energy transfer studies of alkynylplatinum(II) terpyridine complex through interaction with watersoluble poly(phenylene ethynylene sulfonate) and the proof-ofprinciple demonstration of this two-component ensemble for selective label-free detection of human serum albumin," Journal of the American Chemical Society, vol. 133, no. 46, pp. 1877518784, 2011.

[57] G. Accorsi and N. Armaroli, "Taking advantage of the electronic excited states of [60]-fullerenes," Journal of Physical Chemistry C, vol. 114, no. 3, pp. 1385-1403, 2010. 

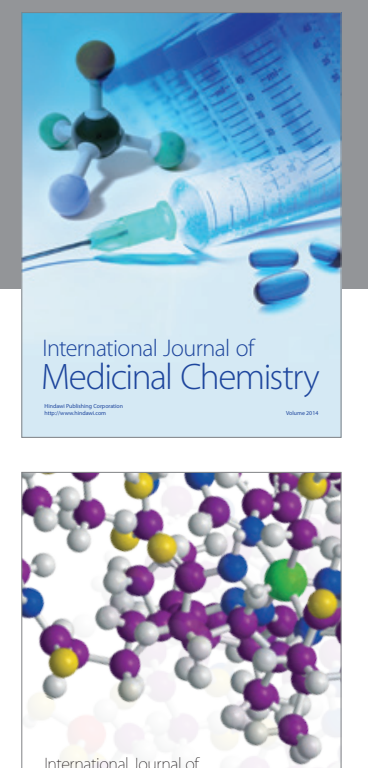

\section{Carbohydrate} Chemistry

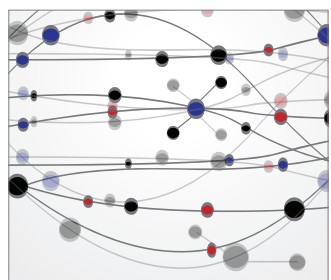

The Scientific World Journal
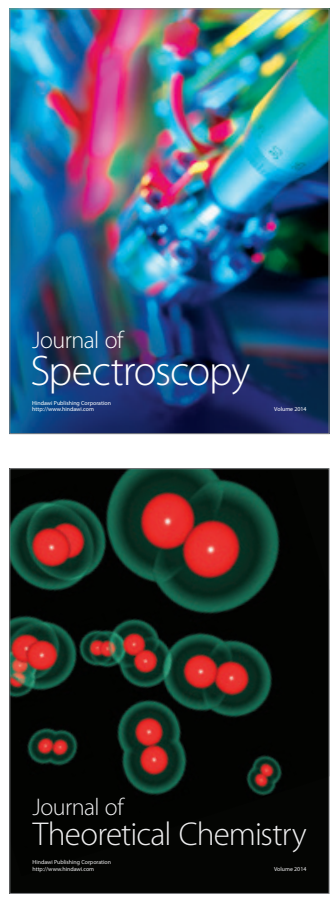
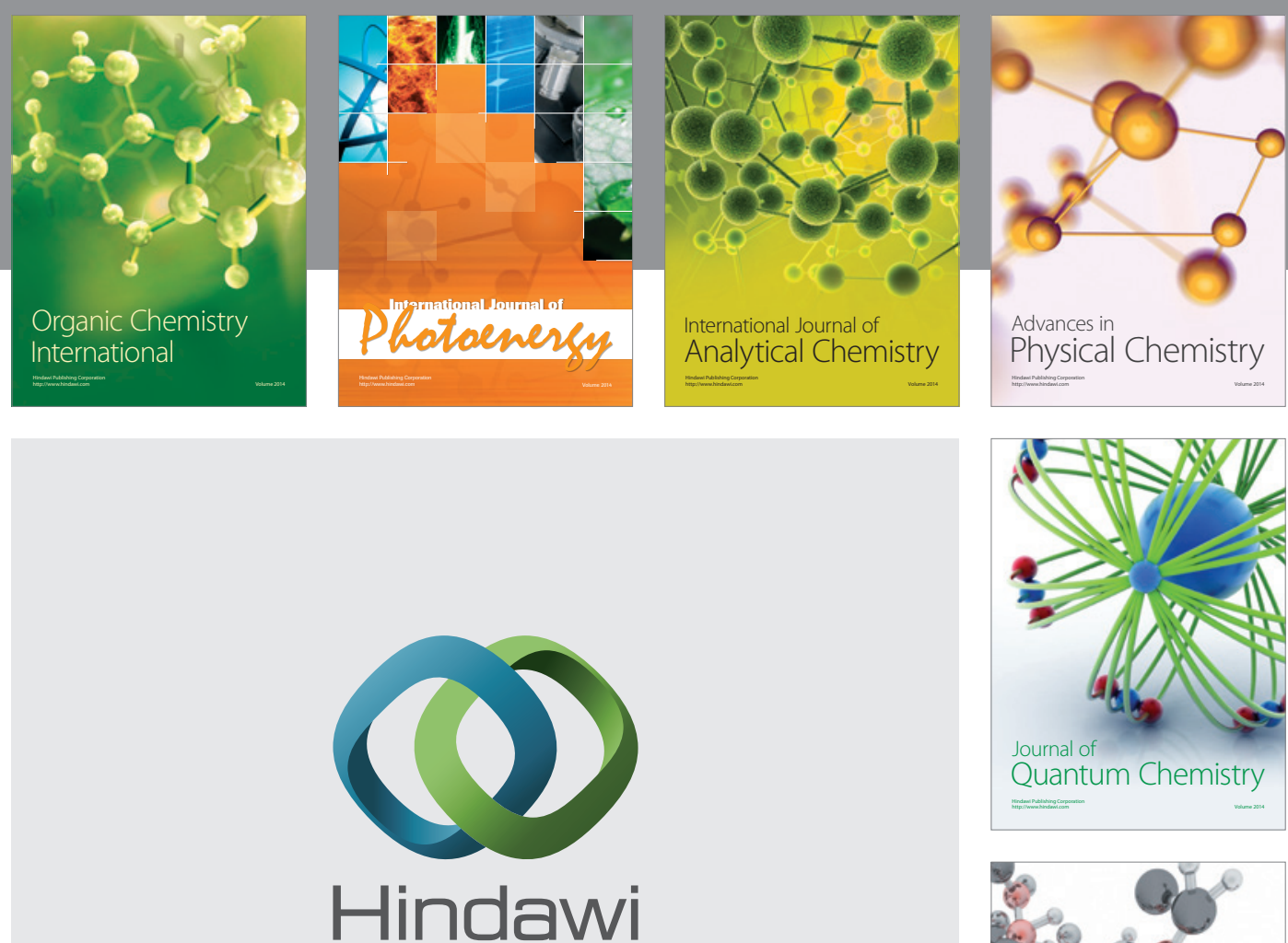

Submit your manuscripts at

http://www.hindawi.com

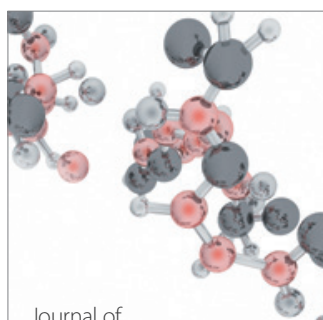

Analytical Methods

in Chemistry

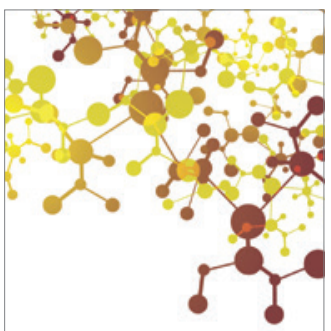

Journal of

Applied Chemistry

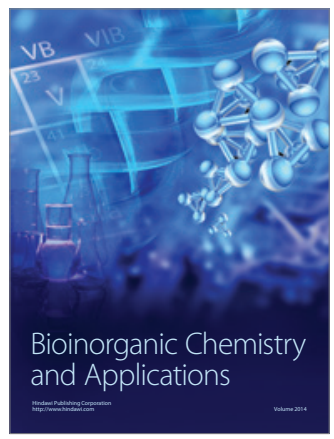

Inorganic Chemistry
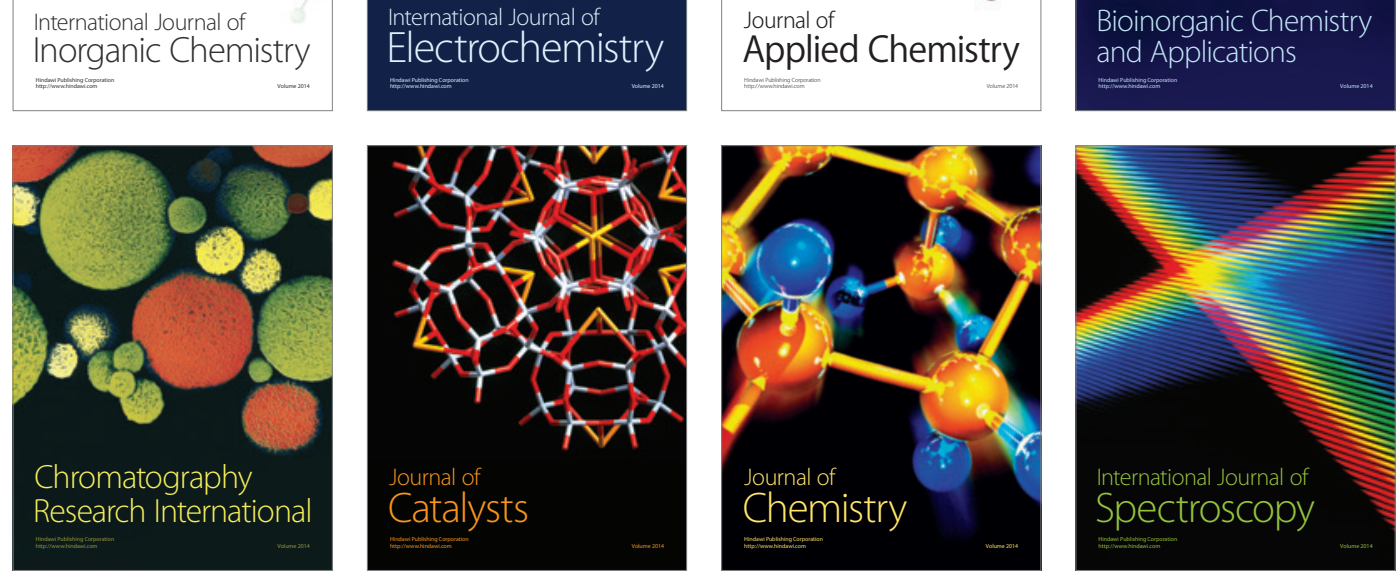